\title{
$\underline{4}$
}

\section{A Commonwealth Initiative to Support Reform of the IMF and the World Bank}

\author{
Ngaire Woods
}

This paper outlines why reform of the IMF and the World Bank has become especially urgent, looks at what is missing from the discussion and makes proposals on how the Commonwealth can contribute to the current debate.

\section{The urgency of reform: why now?}

Both the IMF and the World Bank are undergoing reform. On 28 April 2008 the IMF's Board of Governors adopted 'far-reaching reforms' of the institution's governance structures. Two things are at stake: the organisation's 'credibility and legitimacy' needs rebuilding; ${ }^{1}$ and as emerging economies have turned away from the IMF, its income has plummeted, leaving it with an estimated shortfall of US $\$ 400$ million a year by 2010 and forcing it to lay off 300-400 of its 2,600 staff members.

For the World Bank the crisis is less imminent, but pressures are building. 'Concrete options' for reform have been demanded by the government ministers who oversee the Bank (the Development Committee), who considered the issue in October 2008. The World Bank is calling for 'a process that is inclusive and consultative among shareholders' and delivers rapid results.

Critics argue that the reforms that are being undertaken are nowhere near farreaching enough, and that they amount to little more than tinkering at the edges. Scholars at the Brookings Institution have argued that the proposed package of reforms falls 'far short of the goals of the exercise'. Insiders, on the other hand, say the reforms are the beginning of a dynamic process of change. ${ }^{2}$

The Commonwealth is well situated to help shape this process. It has long been concerned with the Bretton Woods institutions. ${ }^{3}$ It is uniquely placed to represent a wide range of stakeholders, not just because it has members on every continent, but also because of its status and habits as a listening institution.

The stakes are high. Governments all over the world have underscored their hope that the IMF and the World Bank will ensure that appropriate collective action is taken on global financial stability, climate change, food security and the achievement of the millennium development goals, including those on health and education. The current financial crisis demonstrates the need for global action, which the IMF could be uniquely placed to undertake. In development finance there has never been a stronger case for greater multilateral co-operation. As more money and agencies become involved, the World Bank has a unique role as a multilateral forum for negotiations among donors, as 
well as a facilitator of broader co-operation by providing modalities for collaborative development assistance, providing information, reducing the transactions costs of aid and ensuring a better allocation of development finance across countries and sectors.

In many ways the IMF and the World Bank are well placed to deliver on global priorities. They sit at the heart of international economic co-operation with a capacity to lend, set standards, offer policy advice and host negotiations among most countries in the world. They have expert staff, good quality data and long experience of policy in dozens of countries.

What is missing from the IMF and the World Bank as they are currently structured is adequate 'buy-in' from all their members. If either agency is to be effective as a forum for global negotiations or global action, it must inspire political confidence and engagement of countries whose co-operation is vital if the issues listed above are to be addressed. The institutions must be seen as a neutral meeting ground within which key governments can meet and negotiate. Each institution must be perceived and trusted as an impartial arbiter or advisor.

The problem for the IMF and the World Bank is that their governance structures are locked into the past. IMF governance reflects a world in which the USA was the largest creditor and financial stability depended upon decisions made by the USA or G7. Today, the USA is the world's largest debtor and financial stability depends as much on decisions made in Beijing and Dubai as in Washington. The World Bank's governance was created to mobilise capital from Wall Street and on-lend it to developing countries. Today, global development finance is increasingly accessed directly from private sources and from emerging economies such as China, the Gulf States, India and Brazil. Yet both institutions still have their headquarters in Washington DC and US influence is maintained through both formal rules and informal practices.

A further problem is that neither of the institutions has developed as a forum for serious multilateral co-operation. Instead, they have been used mainly to foist change on developing countries. In the words of former IMF Chief Economist Raghuram Rajan: 'some of the largest industrialised countries see themselves as more sovereign than others, and their politicians brook no interference in their own domestic policies, while being fully prepared to use multilateral agencies to intervene in the domestic politics of others' ${ }^{4}$ The institutions' governance structures have made it too easy for industrialised countries to urge others to reform without committing themselves to any of the self-restraining or regulatory actions which are required if the global action mentioned above is to occur.

The current process of reform within the IMF and debate about reform within the World Bank is taking place mainly among their most powerful shareholders and those they have seen fit to include through special individual deals. There is a structural problem with this. Seriously under-represented emerging economies have little incentive to push for reform within formal structures which are tilted against them. The result is that instead of engaging, most are looking for alternatives or taking up special offers in an opportunistic way. They are not formally disengaging, but in practice they are letting the institutions slip to the margins of their policymaking. 


\section{Listening beyond Washington DC}

The voice of emerging countries has for a long time been curiously absent from the debate about how to reform the Bretton Woods institutions. They have not advanced proposals about restructuring - they have too little confidence that such efforts would be repaid. But they do have views on what they need from international co-operation. More importantly, they have views about what kind of institution would command the confidence of other countries.

Views outside Washington DC have been probed and scoped out in various forums. The Global Economic Governance programme has co-hosted four regional consultations with finance officials in Asia, the Middle East, Africa and Central Asia, and collaborated in a meeting of Latin American officials and commentators. These consultations have been focused on the future of the IMF, but have sometimes included discussion about the World Bank. In each consultation, senior finance officials have discussed their needs from global monetary co-operation and the role the international institutions could play. A parallel process was sponsored by the Friedrich Ebert Foundation, whose reports are incorporated in the points made below in relation to the three regions which directly involve Commonwealth countries.

In Asia, the IMF faces a deep crisis of relevance and criticism of its legacy. ${ }^{5}$ The politest view of the IMF's record during the East Asian financial crisis is summed up in the following comment: 'we discovered that the fire brigade was too far away'. Subsequently, some Asian countries have self-insured, stockpiling their own reserves and setting up their own swap arrangements (in the Chiang Mai Initiative), which they are rapidly multilateralising, and developing regional information sharing and standard setting. For these countries, IMF assistance in the future would be politically out of the question and IMF technical or policy advice is deemed 'not relevant'. Countries say: 'they do not have the expertise to advise us'. For these countries, the one use for the IMF in the region is as an indirect arbiter of regional swap arrangements (good standing with the IMF is required to access some of the sums available). The World Bank also plays only a minor role within the region. It is criticised for delivering loans that are of poor quality, with a high proportion of costly technical assistance. Many Asian countries now have access to multiple sources of development financing; indeed, some are now donors in their own right.

Several Asian countries now have alternatives to their previous reliance on the IMF and the World Bank. These countries have become systemically important - they should be included in global dialogue on monetary co-operation, financial stability and development assistance. This poses a significant challenge to the reform process underway in Washington DC. Ask Asian countries in what kind of multilateral institution their governments would have confidence and the answers take you to the foundations of the Bretton Woods settlement. Particularly important are the assurance mechanisms necessary to engage a disaffected and non-needy country or group of countries in closer and deeper global co-operation. 
In the Middle East, the legacy is very different from that in Asia. The countries of the region also differ among themselves. ${ }^{6}$ There are at least three different groups of stakeholders in an area where regional co-operation is patchy and fragmented. In countries with a security crisis - such as Lebanon and the area controlled by the Palestinian Authority - the role of the IMF and the World Bank as impartial and non-political analysts and information-providers has been greatly valued. It is conceivable that once they have been reconfigured the institutions might in the future play a similar role in Iraq. In contrast, a second group of countries, for example Egypt and Jordan, have borrowed in a more traditional way from the IMF and the World Bank - and here there is criticism of the inflexibility and perceived economic interests embedded in the conditionalities attached to Fund and Bank lending in the region. For these countries, the most necessary reform of the institutions concerns their responsiveness. Finally, a third group of stakeholders are non-borrowing creditor countries such as Saudi Arabia and the Gulf States, which are concerned about the governance of the institutions and ensuring that as providers of reserves and development finance their role is formally recognised through adjustments to quota and governance. These countries are significant stakeholders in the global financial system and provide substantial development assistance. For these reasons it is vital to consider what the IMF and the World Bank would look like if these countries were to be more fully engaged.

For countries in the Middle East, the reform of the IMF and the World Bank is important. Creditor countries in the region have their own monetary insurance and development assistance programmes. Even though they have not consolidated regional arrangements in the way that the Asian countries have done, their engagement in the multilaterals cannot be taken for granted. Fundamental governance reform is therefore vital. Borrowing countries in the region value the advisory role of the IMF and the World Bank, but the institutions' programmes need to be far more responsive to the needs of borrowers.

In Africa, there is great anger about the inflexibility of the institutions in spite of the new rhetoric about ownership and streamlined conditionality. ${ }^{7}$ Officials express deep frustration with IMF and World Bank inflexibility and prescriptiveness. As one finance minister put it in May 2008:

... we share the same goals as the IMF but when our situation changes, such as when fuel prices increased last year, and as a government we need to respond to that change, the IMF told us that we could not vary what we have agreed in our programme with them until the next IMF mission comes into town some months later. To our people this makes it look as though the government is unresponsive and incompetent.

Traditionally, African borrowing countries had few choices. However, this is changing. Debt relief and investment by Chinese and other new providers are creating wider choices. Hence, Ghana has become the first African long-term IMF borrower to 'break free' of the institution, as the Ghanaian government sees it. 
The key issue for the IMF and the World Bank is how they can become more responsive to all members, including African countries, through reforming their governance and the operations and management (which are shaped by governance) of individual country programmes. Most African countries need external assistance. Several now have the possibility of loans and investment from new donors. If the IMF is to play an advisory role, it will need to radically refashion the way in which it engages with governments in the region. ${ }^{8}$ The World Bank, meanwhile, has a vital role to play not only as a provider of development finance, but as an institution with the capacity to assist countries in cooperating in development finance - a critical role amidst a proliferation of new stakeholders, including both private investors and aid donors.

In sum, the IMF and the World Bank should be uniquely placed to promote cooperation among governments to ensure global financial stability and partnership in providing development assistance. In practice, serious reform is required to equip them to do this. Where countries are able, they are turning away from the multilateral agencies.

\section{What needs to be done?}

Reinvigorating the IMF and the World Bank to make globalisation more inclusive requires rebuilding the multilateral character of each institution. Emerging economies need to have confidence in the institutions if they are to fully engage. For this, they will need assurance that the institutions belong as much to them as to other countries. At present, they see the institutions as instruments of US or G7 economic interests and values. Equally important, poorer developing countries need institutions that are responsive to elected governments. In spite of longstanding promises to enhance ownership, put governments in the driving seat, and reduce and streamline conditionality, the experience of African negotiators remains, depressingly, the same as it was ten years ago.

It is possible to win the confidence of emerging economies. When the Bretton Woods institutions were created, confidence was created through their governance. In 1944, the original structure of the IMF and the World Bank ensured the engagement of the USA and Wall Street. Since the USA was then the world's largest creditor, as well as the world's largest potential purchaser of World Bank bonds, this confidence was crucial. It was delivered through a system of formal and informal controls.

Specific measures were used to ensure 'buy-in' and engagement to win the confidence of key members, particularly a USA anxious to avoid entanglements. That experience has important lessons for how each agency could be adapted to today's circumstances. The assurance mechanisms in the design of the institutions included control over the headships (and chair of the board) of each organisation; an informal say in the appointments of senior management; weighted voting; a small technocratic board on which the USA had the power of veto over key decisions; and headquarters in Washington DC.

Equally, it is possible to make the institutions more responsive to poorer countries, for example through more robust accountability aimed at results on the ground and through decentralisation, rather than the mitigation of risk in Washington DC. 
The heads of both organisations - and who appoints them and holds them to account during their tenure - are crucial. Until now the Managing Director of the IMF has been appointed by a small group of European countries in consultation with the USA, and the President of the World Bank has been named by the USA. ${ }^{9}$ The heads chair the boards and hold senior management and staff to account, promoting, hiring and firing, and setting directions for each organisation. Their actions are ostensibly supervised by an executive board which is ill-equipped to hold management to account. The result is that the countries who appoint the Managing Director and President skew the accountability of the whole organisation towards themselves. For the wider membership this element of governance underscores the extent to which the IMF and the World Bank are transatlantic, rather than global, organisations. Small moves have been made within the IMF to make the appointment of its Managing Director more meritocratic and transparent. As yet, no such moves have been made by the World Bank.

In each institution decisions are made in ways that provide little incentive for many countries to engage. The rationale is out of date. The formula which allocated to the USA enough votes to give it a power of veto no longer ensures that key stakeholders can participate. On the contrary, it is an obstacle to participation. Missing in both organisations has been an inclusive and trusted process for changing the allocation of votes and the way decisions are made. Put simply, what is now required is for a properly representative group of members, with legitimacy across the full membership, to rewrite not just the voting formula but the decision-making rules of each institution. ${ }^{10} \mathrm{~A}$ change in the Articles of Agreement to effect this would require the agreement of three-fifths of all members having 85 per cent of the total voting power (article XXVIII) and be subject to the provision that no change in a member's quota shall be made without its consent (article III, Section 2(d)).

The location of the institutions is a crucial element in determining whether or not they are perceived to be truly multilateral. The Articles of Agreement require that 'the principal office of the Fund/Bank shall be located in the territory of the member having the largest quota/greatest number of shares'. Each institution may also establish 'agencies or branch offices ... in the territories of other members'. ${ }^{11}$ Although it has been proposed that the boards should be non-resident - an idea with many merits in attempting to promote high-level international co-operation - the location of the agencies is a real block to this. The resident executive boards, which represent (however imperfectly) the full membership, are the thin line between the perception of the IMF and the World Bank as international agencies, rather than as US institutions. That said, location is a core element of the 'assurance' mechanisms mentioned above. Changing location so as to headquarter either institution in a country which was not the principal shareholder would require a change in the Articles of Agreement.

In practice, some authority in each institution is already shifting away from Washington DC. For example, Asian countries have already begun to develop regional monetary arrangements. Their reliance on the IMF as external disciplinarian is less direct than that of other regions. They retain control over their reserves, but delegate an 
agency of restraint function to the IMF. To this extent, the IMF has legitimacy in the region. The challenge now is to define devolutions of authority which suit different regions and groups of countries, so that devolution enhances the legitimacy of the institution, and its responsiveness and effectiveness.

Decentralisation has been the Bank's approach to making itself more responsive to members. In some cases it has devolved significant authority to its country offices, bringing its development lending and advisory work closer to country priorities. In several cases this has proved to be a very successful strategy. Building on this, the Bank's package of governance elements could be better configured to earn the trust of members whose co-operation it requires, as well as to invigorate it as a forum for co-operation on development assistance.

\section{A Commonwealth strategy: three reform agendas}

The countries of the Commonwealth - both large and small - have important interests at stake in reinvigorating the IMF and the World Bank. Effective multilateral institutions are crucial in a changing global economy. As power shifts to emerging economies, their commitment to interstate dialogue and negotiations and to co-operation will be key to resolving issues that include financial stability, development assistance, food security and climate change.

The transformation required in the institutions is one which would lead them to be perceived by members as:

- A neutral forum within which member countries can seriously discuss multilateral cooperation and action;

- Impartial arbiters of internationally agreed standards or codes;

- Unbiased advisers and providers of information.

How might the Commonwealth contribute to the current debate?

- One option is to support the modest reforms which are ongoing within the IMF and that could be extended to the World Bank;

- A second option is to take the current reform debate beyond the institutions themselves, using informal and other formal institutions to ensure a more inclusive debate;

- A third option is to host or support the hosting of a new Bretton Woods-style conference to re-engage countries in multilateral processes.

\section{Scenario 1: The current reform agenda}

Commonwealth governments could opt to do nothing more than continue to support the process already underway. These reforms include the resolution adopted by the IMF Board in 2007 opening the selection process for the head of the organisation to all can- 
didates on an equal basis without regard to nationality. (This resolution was followed by the selection of yet another European to the post.) More recently, three additional measures have been approved. First, voting power in the IMF has always had an element of universality, with a small number of 'basic votes' equally distributed among all countries. The number of basic votes is to be increased slightly to about 5.5 per cent of the total. Second, the votes apportioned according to economic size and openness are also being altered slightly: the quotas of China, Republic of Korea, Mexico and Turkey have already been increased and a second round of ad hoc changes has been approved. ${ }^{12}$ Third, an additional two alternate directors will support the two executive directors who represent 44 African countries in the IMF (with a total of 4.4 per cent of votes). The IMF board is also being urged to use its existing powers to recommend further realignments in quotas and votes every five years.

The positive view of these reforms is that they are the beginning of a process of change. The commitment to deepening the five-year reviews of quotas and votes points in this direction. These changes are already underway. They do not require further determined action by governments, other than gently to nudge the process along. That said, there are serious risks in this scenario.

The World Bank is more or less untouched by the current governance reforms. Put another way, the pressures which have pushed IMF governors and management to respond to demands for change have been inadequate in bringing about changes in the World Bank, whose governance structure reflects that of the IMF because of historical accident. ${ }^{13}$

If no change occurs in the World Bank's governance, this could have grave consequences for the Bank's ability to discharge its present and future responsibilities. The Bank is being asked to take a lead on climate change. Yet at present it is also expected to find new and more responsive ways to work with large emerging economies - who are its fee-paying clients. Without substantial new resources and a new multilateral authority that will set out principles for co-operation on climate change, the Bank's work will soon be full of contradictions.

Dilemmas are already emerging for the World Bank Group. Will the Bank turn down loan requests from powerful emerging economies if they are not climate friendly? The recent support by the International Finance Corporation for the Tata Mundra coal project in Gujarat state in India suggests that it will not. For the Bank to apply stringent new climate change standards to its loans will simply make them unattractive to key clients in the absence of additional resources and much greater credibility as a neutral and impartial setter of international standards.

Similarly, if the Bank is to promote multilateral co-operation on aid, it must engage in a new way with the so-called 'new donors', which include China, the Gulf States and Venezuela. For this reason also the Bank needs governance reform.

Within the IMF, incremental reform may fail to adequately address the urgency of the pressures the IMF is under. In the words of its new Managing Director, the IMF not only faces massive budget cuts this year, but it must reinvigorate both its 'relevance and legit- 
imacy'. Incremental reform risks consigning the IMF to terminal irrelevance before the reform process bears fruit. Its ongoing relevance will depend upon whether members empower it to promote further multilateral co-operation, and provide emergency lending and advice.

In respect of the IMF, there is a risk that the current reforms will do very little to ensure that it is perceived by key members as a neutral forum within which they can seriously discuss multilateral co-operation and action to ensure financial stability or stable exchange rates. The reforms may not be enough to persuade countries that the IMF can act as an impartial fire brigade, close enough to member countries to ensure that the short-term provision of liquidity is rapid and effective, or as a neutral adviser and provider of information on economic policy. Moves to open up the selection of the Managing Director have not yet won credibility. The quota, vote and representation reforms in no way meet the needs and reflections of officials in Asia, Africa and the Middle East. There may well be a structural problem with expecting internal incremental change to produce results.

The push for significant reform in both the IMF and the World Bank is unlikely to come from emerging economies such as China, Republic of Korea, Brazil, Mexico, Argentina and Turkey, who have de facto left the IMF and are much less reliant on the World Bank. Nor is pressure likely to come from developing countries who rely on the institutions for funding, but who see 'exit' as their best option for change. It is also unlikely that the present major shareholders of the institutions will push in a coherent way for reforms which dilute their own relative power, even if individual members are examining various options. For these reasons, other avenues for reforming the IMF and the World Bank need to be considered.

\section{Scenario 2: Pushing reform through the G20 and expanded institutions}

An alternative scenario would be to extend the reform debate beyond the IMF and the World Bank to a more inclusive and consultative forum than the formal structures of the organisations permit. Many propose, for example, that discussion of reform should take place in the G8 or some expanded version of that forum.

Undoubtedly it is useful to expand discussions about the governance and mandate of the financial institutions. Ideally, small groups permit more frank and creative dialogue, opening up a wider range of win-sets to participants. But would this approach really engage those countries who have an incentive to simply go their own way? Is there any evidence that countries outside the $\mathrm{G} 7$ trust such processes?

An expanded G7 grouping has been tried. In the wake of the 1997 East Asian crisis, a G20 finance ministers group was set up explicitly to examine the international financial architecture. On one view, the results of that exercise were a success: the G20 spearheaded discussions which led to the reforms described in scenario 1 above. However, some analysts have noted that although the G20 successfully fostered exchanges among some ministers, in its early years the communiqués resulting from G20 discussions seldom 
went much further than those of the G7. ${ }^{14}$ For many emerging and developing countries, the G20 is perceived as lacking legitimate authority, in large part because it deprives so many countries of formal rights of representation and has little accountability.

The problem with existing forums is that none command sufficient confidence or have the right balance of authority and legitimacy to transform the Bretton Woods institutions. There is a strong case for a fresh way forward.

\section{Scenario 3: A new Bretton Woods-style conference}

If the key to transforming the possibilities of multilateralism is to fully engage important new stakeholders at the heart of multilateral initiatives, then perhaps the exercise needs to be built from the ground up. Key stakeholders must agree an institutional design that gives them assurance about the neutrality of the forum, its impartiality and lack of bias in advice and information. This requires more than tinkering. For all members to believe that the institutions have these attributes, there must be high degrees of representation, participation and accountability.

An obvious successful precedent is the post-war conferences that built and reinforced multilateralism. A new international conference could be called. Its location would have crucial symbolic importance, signalling from the start the intention of the exercise to build a new and more global multilateralism.

A global conference would permit changes to the institutions' Articles of Agreement. Such amendments require a majority of all members as well as a majority of votes. A conference would permit agreement to be sought not just from powerful countries, but from the majority of members.

How could such a negotiation be made effective and participatory? One route would be to structure the conference into: (i) agenda setting, in which all affected countries would have an input and where transparency would be crucial; and (ii) negotiations on the specific design of the institutions, involving key stakeholders (countries without whose co-operation implementation would be impossible), with representation and oversight from regional and collective organisations of smaller members.

The Commonwealth could contribute much to this fresh approach: advising and bringing to bear its knowledge and research; representing those of its members who might otherwise lose out, in particular small states; and overseeing and monitoring the conference on their behalf. Last, but not least, a new conference could learn from the legitimacy the Commonwealth enjoys among its members; their trust in its neutrality, impartiality and lack of bias suggests that the institutional design and structure of the Commonwealth may well have elements relevant to a new multilateralism.

\section{A checklist for Commonwealth governments}

Members of the Commonwealth and the wider global community need multilateral institutions that are effective in promoting co-operation and global action to ensure a more inclusive globalisation. Specifically, many have made it clear that they are looking 
to Heads of Government to reform the Bretton Woods institutions so that they:

- Prevent the destruction of assets by turbulence in financial markets caused by flaws in preventive surveillance and regulation;

- Address climate change by generating and effectively delivering the additional resources needed to import technology, equipment and systems related to the protection of the environment;

- Strengthen lending instruments in developing country financial institutions to promote the entrepreneurship and small and medium-sized enterprises crucial for employment generation and innovation;

- Write off all 'odious debt' to free resources to maintain momentum in reform, debt restructuring and attracting fresh sources of finance;

- Create more comprehensive instruments to cushion small and vulnerable states against natural disasters which inflict disproportionate damage on these fragile economies, through different windows of catastrophe insurance, rapidly dispersing grants and soft loans;

- Create financial facilities to cushion small and vulnerable states against extreme rises in energy, fertiliser and food prices.

If the IMF and the World Bank are to deliver on these aspirations, they need the full engagement of major emerging countries, and they must become more responsive to their smaller, most needy members. Heads of Government need to plan steps to transform the institutions so that they are seen to be genuinely multilateral, as opposed to being owned and operated by the G7.

This is a major task. It requires institutional reforms relating to location, representation, shareholding, voice and transparency. It requires clearer incentives for the institutions to support governments, rather to prescribe to them: supporting stable governments to build and deliver their own national strategies for inclusive development, good governance, and democratic processes and institutions. It requires incentives for the institutions to act with speed and flexibility during democratic transitions and in countries that are emerging from conflict. Nothing short of an international conference to build a new multilateralism is likely to succeed in this. 


\section{Notes}

1 'Transcript of a Conference Call by Senior IMF Officials on Board of Governors Vote Quota and Voice', Washington DC, Tuesday 29 April 2008, www.imf.org/external/np/tr/2008/tr080429a.htm

2 Agustin Carstens, 'Give the IMF's Dynamic New Quota Deal its Due', Financial Times, 15 April 2008.

3 Including through the Commonwealth Finance Ministers group which regularly examines and reports on the roles of the IMF and World Bank.

4 Raghuram G. Rajan, 2008. 'The Future of the IMF and the World Bank', American Economic Review (forthcoming).

5 A meeting of finance officials and commentators from Asia was hosted by the Global Economic Governance Programme, the Centre on East Asian Integration at Beijing University and the Institute of World Economics and Politics at the Chinese Academy of Social Sciences, at Beijing University, 19 September 2007. Further views were expressed by the Indonesian Finance Minister H.E. Dr Sri Mulyani Indrawati at the GEG programme, University College, Oxford, Tuesday 15 January 2008. The Friedrich Ebert Foundation and the Lee Kuan Yew School of Public Policy also hosted a meeting on 'Asian Perspectives on the future role of the IMF' in Singapore, 18 January 2008. See report at http://library.fes.de/pdf-files/iez/global/05169.pdf.

6 A meeting of finance officials and commentators from Arab countries was hosted by the GEG programme and the Centre for International Governance Innovation (CIGI) in Amman, 10 March 2008. Earlier, the Egyptian Finance Minister addressed the GEG programme at a meeting in Oxford, Friday 16 June 2006.

7 A meeting of finance officials and commentators from African countries was hosted by the GEG programme, Debt Relief International and the New Rules Coalition for Global Finance in Maputo, Mozambique, on 15 May 2008. Earlier, the Finance Ministers of South Africa and Nigeria addressed the GEG programme in Oxford on this issue. African health ministers also reflected on their experience of World Bank loans at a GEG programme meeting hosted at Ditchley, UK, 12-13 May 2008. An exchange of views among commentators and civil society groups took place in Tshwane, South Africa, 5-7 November 2008, hosted by the Institute for Global Dialogue and the Friedrich Ebert Stiftung.

8 See The IMF and Aid to Sub-Saharan Africa, report of the Independent Evaluation Office of the IMF, Washington DC, 2007.

9 An implicit part of the same deal has been influence over appointments to senior management positions.

10 This includes the creation of an incentive to powerful vote-holders to consult other countries. Already in both the IMF and the World Bank a double majority is required to alter the Articles of Agreement, as well as to expel a member or deny it benefits. This means that it is not only the votes of powerful countries that matter (an amendment can only be passed with 85 per cent the votes), but that there has to be wider agreement so as to achieve the consent of three-fifths of member countries. Other international organisations also use doublemajority voting (e.g. the EU Council of Ministers and the Global Environment Facility). A double majority voting rule would require powerful countries to build wider alliances so as to gain agreement not just among big vote holders but from a large number of countries. One obvious issue on which a double majority requirement should be applied is the election of the institution heads.

11 IMF Article XIII, IBRD Article 5, section 9.

12 These measures were part of the package agreed at the Spring 2008 annual meeting of the IMF. The underlying formula is being slightly altered so that GDP is valued using a blend of market exchange rates and purchasing power parity rates.

13 The negotiators at Bretton Woods simply ran out of time to plan a separate governance structure for the International Bank for Reconstruction and Development.

14 See Leonardo Martinez, 2007. 'The G20 after Eight Years: How Effective a Vehicle for Developing Country Influence?', Brookings Global Development and Economy Working Paper 12. 